\title{
Restriction enzyme analysis of the mitochondrial genome in mitochondrial myopathy
}

\author{
JOANNA POULTON*, DOUGLAS M TURNBULL†, ATUL B MEHTA , \\ JOHN WILSON\&, AND R MARK GARDINER*
}

From * the Department of Paediatrics, University of Oxford, John Radcliffe Hospital, Oxford, OX 3 9DU; tthe Department of Neurology, The Royal Victoria infirmary, Newcastle upon Tyne NE1 4LP; $\ddagger$ the $\vec{\omega}$ Department of Haematology, Royal Postgraduate Medical School, London W12 0HS; and \$the Department of Neurology, The Hospitals for Sick Children, Great Ormond Street, London WC1N 3JH.

SUMMARY The mitochondrial myopathies are a heterogeneous group of disorders some of which may be caused by mutations in the mitochondrial genome. Mitochondrial DNA from 10 patients은 with mitochondrial myopathy and their mothers was analysed using five restriction enzymes and $\vec{c}$ 11 mitochondrial probes in bacteriophage M13. No abnormalities were found in seven out of the 10 patients. Polymorphisms which have not previously been reported were detected in three ${ }_{\mathbb{D}}^{\circ}$ patients and two of their mothers. These results exclude the presence of deletions or insertions of greater than $60 \mathrm{bp}$ in the region of the mitochondrial genome examined. Any causative mitochondrial DNA mutations in these disorders are therefore likely to be point mutations $\mathrm{gr}_{\overrightarrow{0}}$ small structural rearrangements.

The mitochondrial myopathies comprise a clinically heterogeneous group of disorders characterised by the accumulation of structurally abnormal mitochondria in skeletal muscle. ${ }^{1-3}$

Biochemical studies on mitochondria isolated from skeletal muscle have identified defects at a number of sites including complex I (NADHubiquinone reductase), complex III (ubiquinolcytochrome C oxido-reductase), complex IV (cytochrome oxidase), and ATPase. ${ }^{13}$

The genetic basis of these disorders is uncertain. Of particular interest is the occurrence of a high incidence of maternal transmission in some families. ${ }^{3-5}$ Indeed, there is one extensive pedigree with nine affected subjects and exclusively maternal transmission not explicable by autosomal or $\mathrm{X}$ linked recessive inheritance, where the authors reported the probability of autosomal dominant inheritance to be as low as $0 \cdot 0005 .{ }^{4}$ As mitochondrial DNA is maternally inherited, ${ }^{6}$ this observation led to the suggestion that the pattern of inheritance reflected the transmission of an abnormality within mitochondrial DNA. ${ }^{4}$ While the majority of components of the respiratory chain are encoded in the nucleus, the mitochondrial genome is known to code

Received for publication 5 November 1987.

Revised version accepted for publication 25 January 1988. for apocytochrome B, and some subunits of cytochrome oxidase, ATPase, and complex I. ${ }^{7}$ Functional abnormalities of these components have been $\frac{}{1}$ identified in some patients with mitochondrial $\stackrel{\varrho}{\rightarrow}$ myopathy. It is possible, therefore, that in some of $\overrightarrow{\overrightarrow{0}}$ these patients the causative mutation lies within the mitochondrial rather than the nuclear genome.

Approaches to investigating this problem include analysis of the mitochondrial protein products, $\overline{3}$ which poses considerable technical problems, or of the mitochondrial DNA. The elucidation of the 3 complete sequence of human mitochondrial DNA by Anderson et $a l^{7}$ makes DNA analysis an $\frac{3}{3}$ appropriate alternative. Restriction mapping may be used to identify major alterations and to survey in detail that small segment of the base sequence $\frac{}{2}$ comprising the enzyme recognition sites. However, DNA sequencing is necessary to exclude smaller $\tilde{O}^{\circ}$ changes, such as point mutations, throughout the genome.

In this study restriction mapping has been used as $\mathrm{\omega}$ the necessary preliminary investigation to exclude major DNA alterations in 10 patients with mitose chondrial myopathy and their families. Eleven probes, including those corresponding to regions. ${ }^{\text {? }}$ coding for relevant protein subunits, were used in ${ }^{0}$ order to maximise unambiguous regional detail (fig 1). 


\section{Patients}

Ten patients with mitochondrial myopathy were studied. Details of their clinical features, together with the results of histological and biochemical

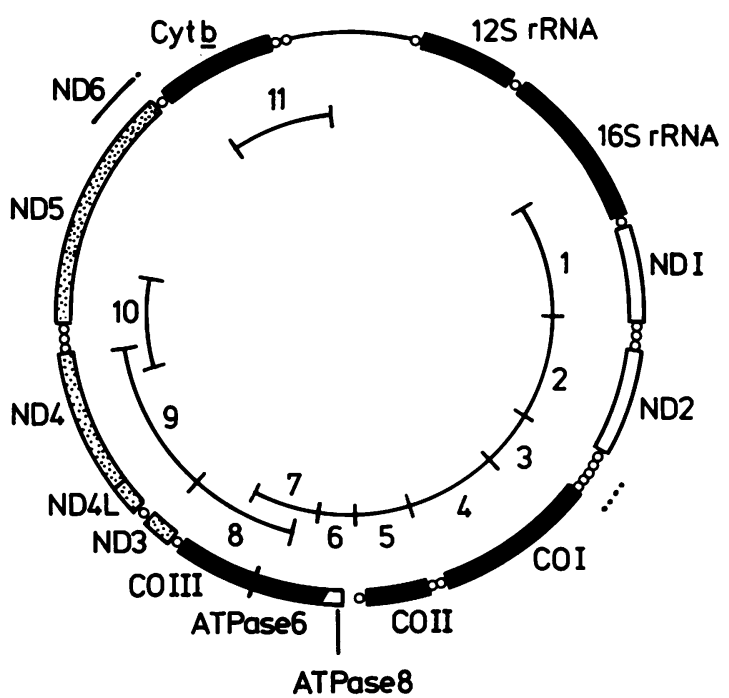

FIG 1 The human mitochondrial genome showing location of probes used. COI to COIII: subunits 1 to 3 of cytochrome C oxidase. ND1 to ND6, and ND4L: subunits 1 to 6 and $4 L$ of NADH-dehydrogenase. ATPase 6 and 8: subunits 6 and 8 of $H^{+}$-ATPase. Cyt b: apocytochrome $B$. 1-11: regions corresponding to probes 1 to 11 referred to in text. O: transfer RNAs. investigations are shown in the table. Nine of the patients' mothers were alive and available for study. One had died from mitochondrial myopathy, and in one case the mother was affected, as demonstrated by histological criteria, and probably both sibs (fig 2). Six patients have been reported previously, as indicated. Normal subjects were included as controls. Ethical permission was granted by the Central Oxford Research Ethics Committee.

\section{Materials}

Restriction enzymes were obtained from Boehringer Mannheim, Amersham International, and Pharmacia, and used according to the manufacturer's instructions. Nylon filters (Hybond $N$ ) and $\left[\alpha-{ }^{32} P\right]$ dCTP (PB 10205, specific activity $3000 \mathrm{Ci} / \mathrm{mmol} /$ )

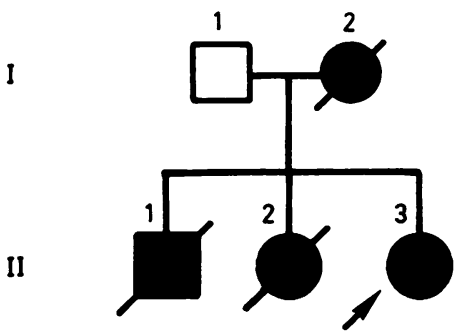

FIG 2 Pedigree of family 6. Patients I.2, II.1, and III.3 all had a similar disease to the proband, apart from age of onset. They died aged 35, 15, and 10 from respiratory failure. Patient II.3 had progressive pain on exercise and weakness from the age of 17 and is now wheelchair bound.

TABLE Patients studied.

\begin{tabular}{|c|c|c|c|c|c|c|c|}
\hline \multirow{2}{*}{$\begin{array}{l}\text { Patient } \\
\text { No }\end{array}$} & \multirow{2}{*}{$\begin{array}{l}\text { Age at } \\
\text { onset }(y)\end{array}$} & \multirow[t]{2}{*}{ Sex } & \multirow{2}{*}{$\begin{array}{l}\text { Clinical } \\
\text { category* }\end{array}$} & \multirow{2}{*}{$\begin{array}{l}\text { Family } \\
\text { history }\end{array}$} & \multicolumn{2}{|c|}{ Investigations } & \multirow[t]{2}{*}{ References } \\
\hline & & & & & $\begin{array}{l}\text { Muscle } \\
\text { histology: } \\
\text { ragged red } \\
\text { fibres }\end{array}$ & $\begin{array}{l}\text { Site of } \\
\text { biochemical } \\
\text { defect: } \\
\text { complex }\end{array}$ & \\
\hline 1 & 14 & $\mathbf{M}$ & I & - & + & I & 9 \\
\hline 2 & 1 & $\mathbf{M}$ & I & - & + & - & \\
\hline 3 & 14 & $\mathbf{M}$ & III & - & + & NAS & 3 \\
\hline 4 & 8 & $\mathbf{M}$ & I & - & $\mathrm{O} \ddagger$ & I \& IV & 10 \\
\hline 5 & 8 & $\mathrm{~F}$ & I & - & + & NAS & \\
\hline 6 & 17 & $\mathbf{F}$ & II & Positive $†$ & + & I & \\
\hline 7 & 4 & $\mathbf{F}$ & III (MELAS) & - & + & NAS & \\
\hline 8 & 9 & $\mathrm{~F}$ & III (MELAS) & - & + & I & 11 \\
\hline 9 & 5 & $\mathbf{M}$ & III (MERRF) & - & + & $\begin{array}{l}\text { V (and } \\
\text { carnitine } \\
\text { deficiency) }\end{array}$ & 3 \\
\hline 10 & 6 & $\mathrm{~F}$ & III (MERRF) & - & + & III \& IV & 3 \\
\hline
\end{tabular}

${ }^{*}$ Clinical categories I, II and III. ${ }^{3}$

tFamily history (see fig 2).

$\ddagger$ Electron microscopy showed abnormal mitochondrial inclusions. Mitochondrial metabolism was previously studied on mitochondria isolated from skeletal muscl. For methods see references 6,10 , and 11

NAS, no abnormality seen.

MELAS, mitochondrial myopathy, encephalopathy, lactic acidosis, and stroke-like episodes. ${ }^{2}$

MERRF, myoclonic epilepsy and ragged red fibres. ${ }^{5}$ 
were obtained from Amersham International. Size markers were obtained from Bethesda Research Laboratories and reagents for oligonucleotide labelling were from Pharmacia. A set of 11 probes consisting of double stranded DNA in bacteriophage M13 complementary to specific regions of the human mitochondrial genome were used (fig 1), by courtesy of Professor G Attardi. These probes are complementary to approximately $83 \%$ of the protein reading frames and $70 \%$ of the total mitochondrial genome.

\section{Methods}

Total cellular DNA was prepared from the white cells of EDTA anticoagulated blood by standard methods. ${ }^{12}$ DNA was digested with each of the following enzymes: AluI, DdeI, HaeIII, HinfI, and TaqI. In selected patients double digests with HinfI and HaeIII and digestion with Bst NI or digestion with StyI were performed. Digested DNA $(3 \mu \mathrm{g})$ was separated by electrophoresis in $2.2 \%$ agarose gels (4 volts $/ \mathrm{cm}$ ) and transferred to nylon filters by Southern blotting. ${ }^{13}$

Probes were labelled to an average specific activity of 1 to $2 \times 10^{9} \mathrm{dpm} / \mu \mathrm{g}$ by the hexanucleotide $\vec{\circ}$ primer method. ${ }^{14}$ Hybridisation was carried out for 12 hours at $65^{\circ} \mathrm{C}(10 \%$ dextran sulphate, $1 \%$ SDS, $5 \times$ Denhardt's, $5 \times$ SSPE, $100 \mathrm{mg} / \mathrm{ml}$ salmon sperm DNA, $125 \mu \mathrm{g} / \mathrm{ml}$ tRNA). Post-hybridisation washes were in $2 \times \mathrm{SSC}, 0.1 \%$ SDS and $0.2 \times \mathrm{SSC}, 0.1 \%$ SDS at $65^{\circ} \mathrm{C}$. Autoradiography (Fuji $x$ ray films) with intensifying screens was at $-70^{\circ} \mathrm{C}$ for 12 to 96 hours.

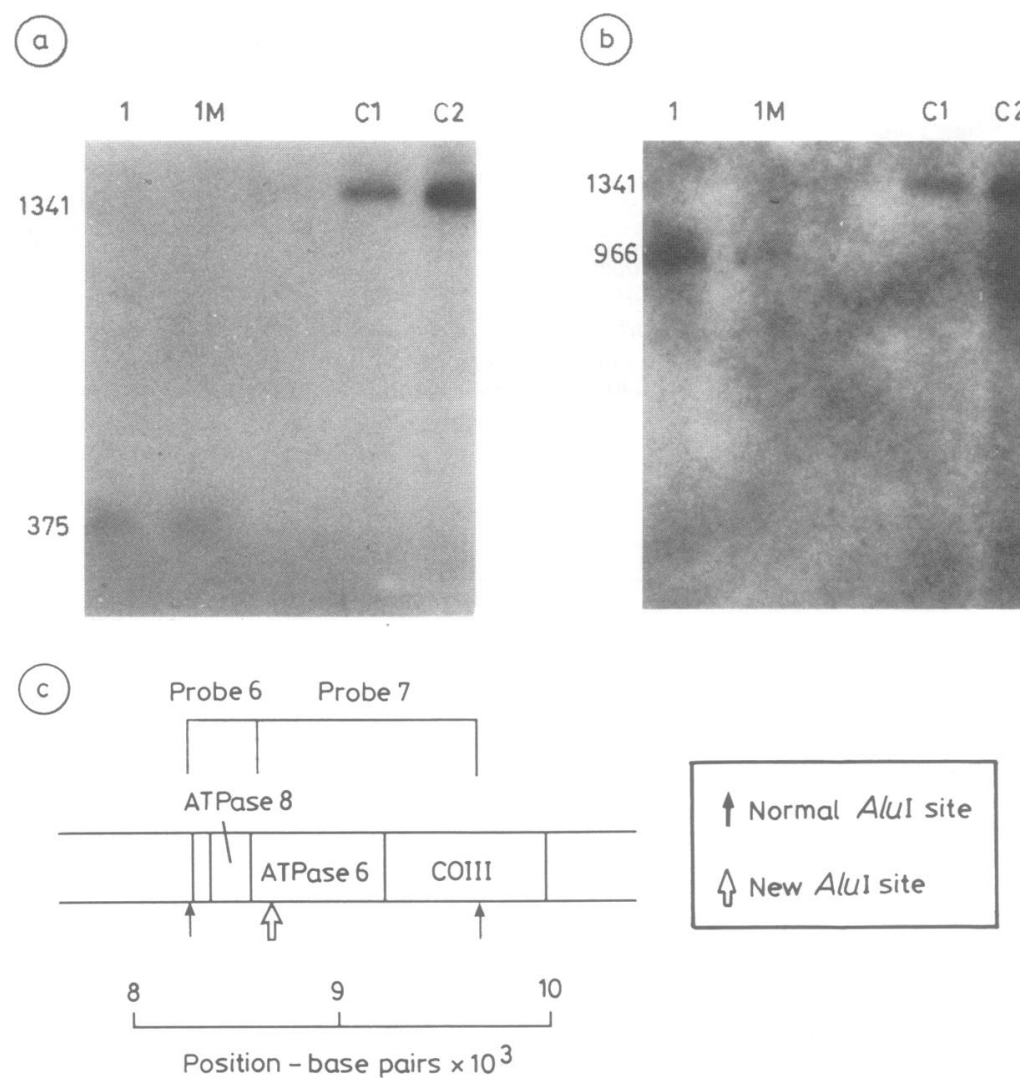

FIG 3 Site changes in case 1. Autoradiographs of AluI digest of case 1 (1), his mother (1M), and two controls $(C 1, C 2)$, hybridised with (a) probe 6 showing replacement of the normal 1341 fragment with a 375 fragment and $(b)$ probe 7 showing replacement of the 1341 fragment with a 966 fragment. (c) Restriction map of bases 8305 to 9645 of the mitochondrial genome. 


\section{Results and discussion}

The restriction fragment sizes predicted from the human mitochondrial DNA sequence ${ }^{7}$ were detected for each combination of restriction enzyme and probe. The smallest fragment size detected was 116 bases. In seven patients the restriction fragments detected did not differ from those predicted from the known sequence and previous population poly- morphism data. ${ }^{7}{ }^{15}$ These results exclude the existence of major rearrangement insertions or deletions of greater than 60 base pairs within the region of the mitochondrial genome examined. They also exclude point mutations within the $5 \%$ of the portion of the mitochondrial genome examined, which comprised the restriction sites surveyed.

New mutations were identified in three patients and in two of their mothers. In patient 1 and his
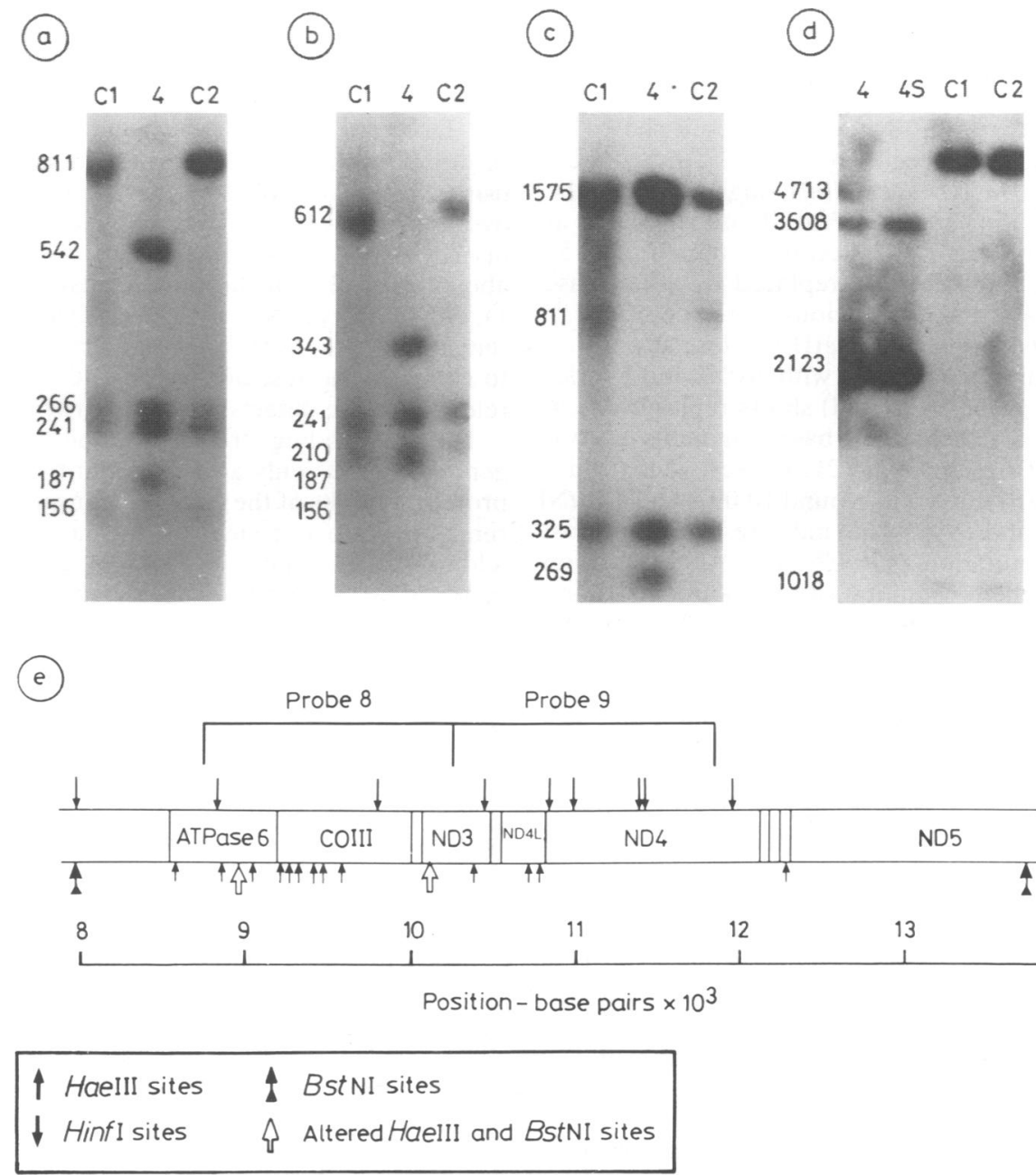

FIG 4 Site changes in case 4. Autoradiographs of (a) HaellI digest of case 4 (4) with two controls $(C 1, C 2)$ hybridised with probe 8 to show replacement of normal 811 fragment by 542 and of normal 187 fragment by 156. (b) Digest with HaelII and HinfI hybridised with probe 8 to show replacement of normal 612 fragment by a 343 fragment and replacement of 156 fragment by 187 fragment. (c) Digest with HaellI hybridised with probe 9 to show replacement of 811 fragment by 269 fragment. (d) Autoradiograph of Bst NI digest of case 4a (4), his sister (4S), and two controls (C1, C2) hybridised, with probe 9 to show replacement of normal 4713 base and 1018 base fragments by 3608 and 2123 fragments. (e) Restriction map of bases 7975 to 13705 of the human mitochondrial genome. 
mother, digestion with AluI resulted in two new fragments of 375 and 966 bases replacing the normal $1.34 \mathrm{~kb}$ fragment. These were shown by probes 6 and 7 , respectively (fig 3). Because transitions occur much more frequently than transversions, ${ }^{16}$ the most likely position can be inferred by searching for semi sites. This suggests a new $A l u I$ site at 8679 base pairs, in the region coding for ATPase subunit 6, caused by an A-G transition which would not result in an amino acid change.

Digestion of DNA from patient 4, his sister, and his mother with HaeIII showed one new polymorphism and one which has been described previously. The normal 811 base fragment is divided into 542 and 269 base pairs at a new HaeIII site shown by probes 8 and 9 , respectively (fig $4 a, c)$. A double digest with HaeIII and HinfI suggests that the mutation creating the new HaeIII site is located at 10097 base pairs (fig 4b). Secondly, the normal 156 base HaeIII fragment was replaced by a 187 base fragment (fig 4a), as has previously been described. ${ }^{15}$ This is consistent with a HaeIII site loss at position 8995. In addition, digestion with Bst NI and hybridisation with probe 10 (fig 4d) shows replacement of the normal 4713 and 1018 base fragments by two fragments of size 3608 and 2123 bases. This, again, suggests a BstNI site gain around 10 097, and a BstNI site loss around 8995 . This indicates that the most likely point mutation at 10097 is an $A-G$ transition lying within the recognition sites of both HaeIII and BstNI. This is the third base in a codon in the reading frame of ND3 and would not result in an amino acid change. Similarly, the most likely cause of the BstNI and HaeIII site losses around 8994 is a G-A transition either at position 8994 or at 8995 . The former is the third base in a codon in the reading frame of ATPase 6, and would not result in an amino acid change; the latter would result in replacement of alanine with threonine.

In patient 3 , digestion with $D d e I$ and hybridisation with probe 11 showed replacement of the 292 band by a 238 band. This site gain could be located at either 15758 or 15945 , and the latter was excluded by obtaining normal restriction fragments with StyI. Thus, the most likely mutation is a G-A transition at 15758 , which would give rise to replacement of an isoleucine residue with valine.

Neither of these two amino acid changes is likely to affect the properties of the proteins substantially. ${ }^{17}$ However, their true location and significance must await further analysis by DNA sequencing and immunoelectrophoresis of protein products.

Two of the three new mutations found in this study were present in asymptomatic mothers of two patients and in one sib, and could therefore be uncommon population polymorphisms of no patho-

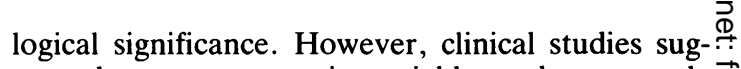
gest that penetrance is variable and apparently $\overrightarrow{\vec{D}}$ unaffected relatives may have histologically abnormal mitochondria. ${ }^{4}$ In addition, age of onset of symptoms may be very variable even within a family $\frac{\bar{c}}{\bar{c}}$ (case 10). Neither of these parents has been $\frac{\overrightarrow{\mathbb{\Phi}}}{\mathrm{\sigma}}$

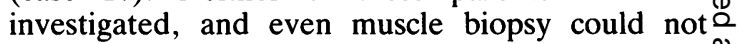
unequivocally exclude a mild defect in an unbiopsied muscle. There have been only two previously $\vec{O}$ reported DNA studies of mitochondrial myopathy. ${ }^{1819}$ Although they identified population $\vec{\omega}$ polymorphisms, they did not find any alterations? which they considered to be of pathological significance. Both of these studies used total mitochond-in rial DNA as a probe, which may give ambiguous results. Our study has taken this a step further by using a series of probes to give more regional detail 0 over a range of patients and has excluded deletions, 옥 insertions, or rearrangements of 60 base pairs or $\rightarrow$ above from $83 \%$ of the protein reading frames (fig $\mathcal{\Phi}$ 1). Regional probes were not available for the $\underset{\mathbb{P}}{\mathbb{O}}$ remaining $17 \%$, as this region is peculiarly resistant $\frac{\mathbb{Q}}{3}$ to cloning. The rest of the genome is probably not relevant to the defects in these particular patients.

The 13 reading frames of the mitochondrial $\overrightarrow{0}$ genome encode only a small minority of the knowno protein subunits of the electron transport chain. The remainder are encoded by nuclear genes, and addition there must be many regulatory genes involved in assembly. These figures suggest that most cases of mitochondrial myopathy are the result $\frac{\circ}{\otimes}$ of mutations in nuclear genes and would occur $\stackrel{\varrho}{\rightarrow}$ sporadically or follow an autosomal recessive inheri-을 tance pattern. The majority of biochemical defects in man have such a mode of inheritance. ${ }^{20}$ However, Wallace $e t a l^{21}$ have pointed out that the higher mutation rate of mitochondrial DNA as compared with nuclear DNA may increase the likelihood of fixation for mitochondrial mutations. If so, a mito- $\frac{3}{3}$ chondrial mutation is a reasonable hypothesis in families with apparent maternal inheritance.

The patients in this study were a representative group of cases of mitochondrial myopathy occurring? after the neonatal period, ${ }^{1-322}$ and in no case was the diagnosis in doubt. Mitochondrial DNA extracted from white cells is almost certainly identicalN to that found in skeletal muscle, ${ }^{23}$ although heteroplasmy occurs rarely in cows. ${ }^{24}$ However, hetero- $N$ plasmy does remain a theoretical possibility andw might conceivably explain the distribution of affected tissues in mitochondrial myopathy and theo variation in severity within a family. In this unlikelyळ event, mitochondrial DNA from white cells might: be unrepresentative and not reflect the type found in skeletal muscle.

In conclusion, these results show that large

.


deletions or insertions are not present in the mtDNA of. a representative selection of patients with mitochondrial myopathy. If these disorders result from mutations in mitochondrial DNA these are likely to be point mutations or small structural rearrangements.

Changes in restriction fragment size explicable by such mutations were observed in three out of 10 patients. It is likely that these represent silent population polymorphisms. Identification of pathologically significant mutations in the mitochondrial genome of patients with mitochondrial myopathy will require sequence analysis of appropriate regions and biochemical studies of the corresponding protein subunit.

Dr J Poulton was in receipt of an Action Research Training Fellowship. This work was supported by the Oxford University Medical Research Fund and the EP Abraham Trust. We are grateful to Professor $G$ Attardi for making the probes available. We are grateful to Drs Judith Hockaday, Joyce Burke, and Christopher Davis for allowing us to study patients under their care. We thank Mr Richard Woods and Miss Minakshi Joshi for excellent technical assistance and Miss Gail Davies for typing the text.

\section{References}

${ }^{1}$ Morgan-Hughes JA, Hayes DJ, Clark JB, et al. Mitochondrial encephalomyopathies. Brain 1982;105:553-82.

2 DiMauro S, Bonilla E, Zeviani M, Nakagawa M, DeVivo DC. Mitochondrial myopathies. Ann Neurol 1985;17:521-38.

${ }^{3}$ Petty RKH, Harding AE, Morgan-Hughes JA. The clinical features of mitochondrial myopathy. Brain 1986;109:915-38.

${ }^{4}$ Egger J, Wilson J. Mitochondrial inheritance in a mitochondrially mediated disease. N Engl J Med 1983;309:142-6.

5 Rosing HS, Hopkins LC, Wallace DC, Epstein CM, Weidenheim K. Maternally inherited mitochondrial myopathy and myoclonic epilepsy. Ann Neurol 1985;17:228-37.

6 Giles RE, Blanc H, Cann HM, Wallace DC. Maternal inheritance of human mitochondrial DNA. Proc Natl Acad Sci USA 1980;77:6715-9.

7 Anderson S, Bankier AT, Barrell BG, et al. Sequence and organisation of the mitochondrial genome. Nature 1981;290: 457-65.

${ }^{8}$ Chomyn A, Mariottini P, Cleeter MWJ, et al. Functional assignment of the products of the unidentified reading frames of human mitochondrial DNA. In: Quagliariello E, et al, eds.
Achievements and perspectives of mitochondrial research. Vol II. Biogenesis. Amsterdam: Elsevier, 1985:259-75.

9 Land JM, Hockaday JM, Hughes JT, Ross BD. Childhood mitochondrial myopathy with ophthalmoplegia. J Neurol Sci 1981;51:371-82.

${ }^{10}$ Turnbull DM, Johnson MA, Dick DJ, Cartlidge NEF, Sherratt HSA. Partial cytochrome oxidase deficiency without subsarcolemmal accumulation of mitochondria in chronic progressive external ophthalmoplegia. J Neurol Sci 1985;70:93-100.

11 Hayes DJ, Hilton-Jones D, Arnold DL, et al. A mitochondrial encephalomyopathy. J Neurol Sci 1985;71:105-18.

12 Old JM, Higgs DR. Gene analysis. In: Weatherall DJ, ed. The thalassaemias. Methods in haematology. Vol 6. Edinburgh: Churchill Livingstone, 1983:74-102.

${ }^{13}$ Southern EM. Detection of specific sequences among DNA fragments separated by gel electrophoresis. J Mol Biol 1975;98: 503-15.

${ }^{14}$ Feinberg A, Vogelstein B. A technique for radiolabelling DNA restriction endonuclease fragments to high specific activity. Anal Biochem 1983;132:6-13.

15 Cann RL, Stoneking M, Wilson AC. Mitochondrial DNA and human evolution. Nature 1987;325:31-6.

16 Cann RL, Brown WM, Wilson AC. Polymorphic sites and the mechanism of evolution in human mitochondrial DNA. Genetics 1984;106:479-99.

17 Grantham R. Amino acid difference formula to help explain protein evolution. Science 1974;185:862-4.

18 Wallace DC, Singh G, Hopkins LC, Novotny EJ. Maternally inherited diseases of man. In: Quagliariello E, et al, eds Achievements and perspectives of mitochondrial research. Vol II. Biogenesis. Amsterdam: Elsevier, 1985:427-36.

19 Harding AE, Holt IJ, Morgan-Hughes JA. Restriction enzyme analysis of mitochondrial DNA in patients with mitochondrial myopathy. J Med Genet 1987;24:243A.

20 McKusick VA. Mendelian inheritance in man. 6th ed. Baltimore: Johns Hopkins University Press, 1983.

21 Wallace DC, Ye J, Neckelmann N, Singh GP. Mitochondrial genetic variation and neuromuscular disease. Predominance of mtDNA versus nDNA mutations in ATP synthetase genes. Seventh International Congress of Human Genetics, Berlin, 1986. Berlin: Springer Verlag (in press).

22 Egger J, Lake BD, Wilson J. Mitochondrial cytopathy. A multisystem disorder with ragged red fibres on muscle biopsy. Arch Dis Child 1981;56:741-52.

${ }^{23}$ Monnat RY, Loeb LA. Nucleotide sequence preservation of human mitochondrial DNA. Proc Natl Acad Sci USA 1985;82: 2895-9.

${ }^{24}$ Hauswirth WW, Laipis $P$. Transmission genetics of mammalian mitochondria: a molecular model and experimental evidence. In: Quagliariello E, et al, eds. Achievements and perspectives of mitochondrial research. Vol II. Biogenesis. Amsterdam: Elsevier, 1985:49-59.

Correspondence and requests for reprints to $\mathrm{Dr}$ Joanna Poulton, Department of Paediatrics, John Radcliffe Hospital, Headington, Oxford OX3 9DU. 